\title{
PENGETAHUAN MENGENAI KEPUTIHAN PADA REMAJA PUTRI DI SMA NEGERI 4 MEDAN
}

\author{
Dina Indarsita \\ Jurusan Keperawatan Politeknik Kesehatan Kementrian Kesehatan Medan
}

\begin{abstract}
Abstrak
Remaja merupakan masa peralihan dari masa kanak-kanak menuju dewasa. Salah satu organ yang berkembang pada remaja khususnya wanita adalah organ reproduksi. Deteksi dini kesehatan organ reproduksi bisa dilihat dari jenis keputihan yang sering dialami remaja wanita. Tujuan mengetahui jenis keputihan yang dialami adalah untuk mencegah terjadinya penyakit reproduksi sejak dini. Tujuan penelitian ini adalah untuk mengetahui gambaran pengetahuan remaja putri mengenai keputihan di SMA Negri 4 Medan tahun 2017. Jenis penelitian yang dilakukan adalah penelitian deskriptif. Pada penelitian ini jumlah populasi adalah seluruh siswi kelas XIdi SMA Negeri 4 Medan sebanyak 274 orang dan yang menjadi sampel yaitu sebanyak 138 orang. Teknik pengambilan sampel dengan menggunakan teknik simple random sampling. Pengumpulan data dilakukan dengan menggunakan kuesioner. Analisis data dilakukan dengan mencari pengetahuan tentang pemeriksaan payudara sendiri pada remaja putri. Hasil penelitian yang dilakukan pada 138 orang responden diperoleh mayoritas responden yang mengetahui keputihan dengan kategori cukup berjumlah 73 orang (52,9\%).Dari hasil penelitian tersebut maka diharapkan pihak sekolah, orang tua, dan petugas kesehatan sekitar dapat berperan aktif dalam memberikan informasi mengenai keputihan pada siswi tersebut.
\end{abstract}

Kata kunci : Keputihan, Remaja Putri, Pengetahuan

\section{PENDAHULUAN}

Remaja merupakan masa peralihan dari masa kanak-kanak menuju dewasa. Pada periode ini, remaja mengalami pubertas. Selama pubertas, remaja mengalami perubahan hormonal dan mengalami perubahan dramatis dalam bentuk perubahan fisik.Perubahan fisik yang terjadi pada remaja putri seperti pertumbuhan payudara, kematangan organ reproduksi dan pertumbuhan rambut genitalia yang mengiringi masa pubertas pada remaja (Leli, 2012).

Keputihan atau flour albus adalah kondisi vagina saat mengeluarkan cairan atau lendir menyerupai nanah. Keputihan tidak selamanya merupakan penyakit karena ada juga keputihan yang normal. Oleh karena sebab itu, keputihan dibagi menjadi dua, yaitu keputihan normal dan keputihan abnormal (Hamid, 2012).

Populasi remaja di kota Medan berdasarkan data Badan Pusat Statistik (BPS) kota medan, ditahun 2013 berjumlah 636.464 jiwa, tahun 2014 berjumlah 651.479 jiwa, dan 2015 berjumlah 649.908 jiwa. Hal ini berarti populasi remaja di kota medan mengalami peningkatan yang cukup pesat dari tahun 2013 ke tahun 2014, dan mengalami penurunan di tahun 2015, namun tidak dalam jumlah besar.

Berdasarkan penelitian Paryono dkk tahun 2016 dari 41 siswi, diperoleh hasil, semua responden mengalami keputihan dan gatal (100\%), 27 siswi (65,9\%) mengalami keputihan fisiologi, dan 14 remaja $(34,1 \%)$ mengalami keputihan patologi. Demikian dengan hasil penelitian Dinda dkk 2016 terdapat 226 remaja putri di desa Cilayung yang mengalami keputihan. Paryono dkk 2016 mengatakan "Hampir 75\% wanita di Indonesia mengalami keputihan dalam hal ini tidak terkecuali remaja putri. Survey menunjukkan 65\% remaja putri mengalami keputihan. Hasil penelitian menunjukkan pengetahuan siswi rendah tentang keputihan 51,8\% sikap siswi mendukung upaya pencegahan keputihan 69,6\%, melakukan upaya pencegahan keputihan baik 50,0\%. Hasil lain menunjukan sikap dan perilaku remaja dalam mencegah keputihan, yang memiliki kategori baik 25,86\%, cukup 67,24\%, dan kurang 6,8\%”.

Dinda dkk 2016 mengatakan "Berdasarkan data Survei Kesehatan Reproduksi Remaja Indonesia (SKRRI) tahun 2010 menunjukan bahwa wanita yang rentan mengalami keputihan yaitu wanita yang berusia 15-24 tahun. Gejala keputihan yang dialami oleh remaja putri, dalam 12 bulan terakhir menunjukkan remaja tersebut cukup banyak sebesar 31,8\%. Ini menunjukkan remaja putri mempunyai risiko lebih tinggi terhadap infeksi atau keputihan patologis".

Siti dkk 2015 mengatakan "Ada banyak penyebab dari keputihan namun paling sering disebkan oleh infeksi jamur candida, bakteri parasit seperti trikomonas yang menyebabkan peradangan pada vagina dan sekitarnya. Untuk menghindari komplikasi yang serius dari keputihan, sebaiknya penatalaksanaan dilakukan 
sedini mungkin seperti melalui personal highline yang baik dan perawatan pada genetalia eksterna”.

Sebagian penderita keputihan mengeluh rasa gatal pada kemaluan dan lipatan paha, rasa panas di bibir vagina, serta nyeri ketika buang air kecil dan berhubungan seksual. Rasa gatal tersebut bisa terjadi terus-menerus atau hanya sesekali, misalnya pada malam hari. Hal ini diperparah oleh kondisi lembab, karena banyaknya cairan yang keluar di sekitar paha, sehingga kulit di bagian itu mudah lecet. Lecet-lecet tersebut semakin parah karena garukan yang dilakukan ketika merasa gatal (Hamid, 2012).

Untuk menangani masalah diatas remaja perlu meningkatkan pengetahuannya, berdasarkan hasil penelitian Siti dkk 2015,menunjukkan bahwa karakteristik remaja putri di SMK Negeri 1 Kota Tegal adalah sebagian besar berumur 15-17 tahun (61,6\%), tingkat ekonomi $\geq$ UMR (74\%) dan status kesehatan sehat(76,7\%). Berpengetahuan cukup tentang keputihan (41,1\%), dimana responden sebagian besar berpengetahuan cukup tentang pengertian keputihan (52,1\%), dan sebagaian besar berpengetahuan kurang terhadap tanda dan gejala keputihan (57,5\%), penyebab keputihan (42,5\%), klasifikasi keputihan (50,7\%), perawatan kejadian keputihan $(65,8 \%)$ dan pencegahan kejadian keputihan (67,1\%).

Demikian dengan hasil penelitian Dinda dkk 2016, dapat diketahui bahwa pengetahuan remaja putri dalam penanganan keputihan dalam kategori baik sebesar 61,7\%, cukup sebesar 27,2\%, dan kurang sebesar 11,1\%. Dan hasil penelitian Paryono dkk 2016 dapat diketahui bahwa sebagian besar remaja sudah mendapatkan informasi mengenai keputihan sebanyak 25 siswi (61\%), dan yang belum pernah mendapat informasi sebanyak 16 siswi (39\%).

Berdasarkan survey pendahuluan yang dilakukan peneliti pada tanggal 3 Februari 2017 jumlah seluruh siswi SMA Negri 4 Medan sebanyak 903 orang, dengan populasi seluruh siswi kelas XI sebanyak 274 orang dan adapun hasil wawancara pada 10 orang siswi yang dipilih secara acak mengenai keputihan, didapat 7 orang (70\%) mengatakan tidak tahu mengenai keputihan, 1 orang mengatakan pernah mendengar keputihan, dan 2 orang mengerti mengenai keputihan.

Berdasarkan data diatas peneliti tertarik untuk meneliti bagaimana pengetahuan remaja putri mengenai keputihan di SMA Negri 4 Medan.

\section{METODE}

Penelitian ini menggunakan jenis penelitian deskriptif yaitu suatu metode penelitian yang dilakukan dengan tujuan utama untuk membuat gambaran atau deskripsi tentang suatu keadaan secara objektif dengan desain penelitian pendekatan cross sectional.

Penelitian ini dilakukan di SMA Negri 4 Medan yang terletak di Jl. Gelas No 12 Medan. Penelitian ini pada bulan Februari 2017 s/d Juni 2017.dilakukan

Populasi pada penelitian ini adalah remaja putri kelas XI di SMA Negeri 4 berjumlah 274 orang (12 kelas) tahun 2017. Menurut Taro Yamane dan Slovin, apabila jumlah populasi (N) diketahui maka untuk pengambilan sampel dapat menggunakan rumus sebagai berikut: (Ridwan \& Akdon, 2010)

$$
\begin{aligned}
& \mathrm{n}=\frac{N}{1+N\left(d^{2}\right)} \\
& \mathrm{n}=\frac{274}{1+274\left(0,06^{2}\right)} \\
& \mathrm{n}=\frac{274}{1+274(0,0036)} \\
& \mathrm{n}=\frac{274}{1+0,9864} \\
& \mathrm{n}=137,9 \\
& \mathrm{n}=138 \text { orang }
\end{aligned}
$$

Adapun teknik pengambilan sampel yang diambil oleh peneliti pada setiap kelas ialah dengan menggunakan teknik simple random sampling. Cara pengambilan secara simple random sampling dengan menggunakan undian yang diambil dari nomor absen siswa remaja putri kelas XI di SMA Negeri 4 Medan.

Alat pengumpul data yang digunakan pada penelitian ini adalah kuesioner tentang pengetahuan mengenai keputihan. Adapun kuesioner pengetahuan berjumlah soal dengan cara pengisian yaitu memberi tanda silang (x) pada jawaban yang telah disediakan.

\section{HASIL DAN PEMBAHASAN}

\section{A. Hasil Penelitian}

1. Pengetahuan Mengenai Keputihan

Tabel 1. Distribusi Frekuensi Pengetahuan Responden Mengenai Keputihan Di SMA Negri 4 Medan Tahun 2017

\begin{tabular}{llll}
\hline No & Pengetahuan & F & $\%$ \\
\hline 1. & Baik & 22 & 15,9 \\
2. & Cukup & 73 & 52,9 \\
3. & Kurang & 43 & 31,2 \\
\hline & Total & 138 & 100 \\
\hline
\end{tabular}

Berdasarkan tabel 1 di atas diketahui bahwa mayoritas responden yang mengetahui keputihan yang pengetahuannya cukup berjumlah 73 orang (52,9\%) dan minoritas responden pengetahuan baik 22 orang $(15,9 \%)$.

2. Sumber Informasi

Tabel 2. Distribusi FrekuensiSumber Informasi Responden Di SMA Negri 4 Medan Tahun 2017

\begin{tabular}{llll}
\hline No & Sumber Informasi & $\mathrm{F}$ & $\%$ \\
\hline 1. & Media Elektronik & 93 & 67,4 \\
2. & Media Cetak & 18 & 13 \\
3. & Orang & 27 & 19,6 \\
\hline & Total & 138 & 100 \\
\hline
\end{tabular}

Berdasarkan tabel 2 di atas diketahui bahwa mayoritas responden yang mendapatkan sumber informasi melalui media elektronik sebanyak 93 orang $(67,4 \%)$ dan minoritas responden mendapatkan sumber informasi melalui media cetak sebanyak 18 orang (13\%). 
3. Pendidikan Orang Tua

Tabel 3. Distribusi Frekuensi Pendidikan Orang Tua Responden Di SMA Negri 4 Medan Tahun 2017

\begin{tabular}{llll}
\hline No & Pendidikan Orang Tua & F & $\%$ \\
\hline 1. & SMA & 77 & 55,8 \\
2. & Perguruan Tinggi & 61 & 44,2 \\
\hline & Total & 138 & 100 \\
\hline
\end{tabular}

Berdasarkan tabel 3 di atas diketahui bahwa mayoritas responden yang orang tuanya berpendidikan SMA sebanyak 77 orang $(55,8 \%)$ dan minoritas responden yang oranng tuanya berpendidikan perguruan tinggi sebanyak 61 orang (44,2\%).

4. Pekerjaan Orang Tua

Tabel 4. Distribusi Frekuensi Pekerjaan Orang Tua Responden Di SMA Negri 4 Medan Tahun 2017

\begin{tabular}{llll}
\hline No & Pekerjaan org tua & F & $\%$ \\
\hline 1. & Petani & 3 & 2,2 \\
2. & PNS & 51 & 37 \\
3. & Wiraswata & 72 & 52,2 \\
4. & Buruh & 12 & 8,7 \\
\hline & Total & 138 & 100 \\
\hline
\end{tabular}

Berdasarkan table 4 di atas diketahui bahwa mayoritas responden yang orang tuanya memiliki pekerjaan sebagai wiraswasta sebanyak 72 orang $(52,2 \%)$ dan minoritas responden yang oranng tuanya memiliki pekerjaan sebagai petani sebanyak 3 orang $(2,2 \%)$.

5. Pengetahuan Keputihan dan Sumber Informasi Tabel 5. Distribusi

FrekuensiPengetahuan

Responden Menganai Keputihan

Berdasarkan Sumber Informasi Di SMA Negri 4 Medan Tahun 2017

\begin{tabular}{llllllllll}
\hline & & \multicolumn{9}{c}{ Sumber Informasi } & \multirow{2}{*}{ Total } \\
\cline { 2 - 8 } Nc Pengetahuar & $\begin{array}{l}\text { Media } \\
\text { Elektronik }\end{array}$ & \multicolumn{4}{l}{$\begin{array}{l}\text { Media } \\
\text { Cetak }\end{array}$} & \multicolumn{2}{c}{ Orang } & & \\
\cline { 2 - 8 } & & F & $\%$ & F & $\%$ & F & $\%$ & F & $\%$ \\
\hline 1 & Baik & 16 & 72,7 & 4 & 18,2 & 2 & 9.1 & 22 & 16 \\
2 & Cukup & 49 & 67,1 & 7 & 9.6 & 17 & 23,3 & 73 & 53 \\
3 & Kurang & 28 & 65,1 & 7 & 16,3 & 8 & 18,6 & 43 & 31 \\
\hline Total & 93 & 67,4 & 18 & 13 & 27 & 19,6 & 138 & 100 \\
\hline
\end{tabular}

Berdasarkan tabel 5 diatas diketahui bahwa mayoritas responden yang mengetahui keputihan yang pengetahuannya cukup dan mendapat informasi melalui media elektronik sebanyak 49 orang $(67,1 \%)$ dan minoritas responden yang mengetahui keputihan yang pengetahuannya baik dan mendapat informasi melalui orang sebanyak 2 orang $(9,1 \%)$.
6. Pengetahuan Keputihan dan Pendidikan Oang Tua

Tabel 6. Distribusi Frekuensi Pengetahuan RespondenMengenai Keputihan Berdasarkan Pendidikan Orang Tua Di SMA Negri 4 Medan Tahun 2017

\begin{tabular}{|c|c|c|c|c|c|c|}
\hline \multirow{3}{*}{$\mathrm{Nc}$} & \multirow{3}{*}{ Pengetahuan } & \multicolumn{3}{|c|}{ Pendidkan Orang Tua } & \multirow{2}{*}{\multicolumn{2}{|c|}{ Total }} \\
\hline & & \multicolumn{2}{|c|}{ SMA } & $\begin{array}{l}\text { Perguruan } \\
\text { Tinggi }\end{array}$ & & \\
\hline & & $\mathrm{F}$ & $\%$ & F \% & $\mathrm{F}$ & $\%$ \\
\hline 1 & Baik & 11 & 50 & 1150 & 22 & 16 \\
\hline 2 & Cukup & 37 & 50,6 & 3649,4 & 73 & 52 \\
\hline 3 & Kurang & 29 & 67,4 & 1432,6 & 43 & 31 \\
\hline \multicolumn{2}{|c|}{ Total } & 77 & 55,7 & 6144,3 & 138 & 100 \\
\hline
\end{tabular}

Berdasarkan tabel 6 diatas diketahui bahwa mayoritas responden yang mengetahui keputihan yang pengetahuannya cukup dan pendidikan orang tuanya SMA sebanyak 37 orang (50,6\%) dan minoritas responden yang mengetahui keputihan yang pengetahuannya baik dan pendidikan orang tuanya SMA dan perguruan tinggi sebanyak 11 orang (50\%).

7. Pengetahuan Keputihan dan Pekerjaan Orang Tua

Tabel 7. Distribusi Frekuensi Pengetahuan Responden Mengenai Keputihan

Berdasarkan Pekerjaan Orang Tua Di SMA Negri 4 Medan Tahun 2017

\begin{tabular}{|c|c|c|c|c|c|c|c|c|c|c|}
\hline \multirow{3}{*}{ No Pengetahuan } & \multicolumn{8}{|c|}{ Pekerjaan Orang Tua } & \multirow{2}{*}{\multicolumn{2}{|c|}{ Total }} \\
\hline & \multicolumn{2}{|c|}{ Petani } & \multicolumn{2}{|c|}{ PNS } & \multicolumn{4}{|c|}{ Wiraswasta Buruh } & & \\
\hline & $\bar{F}$ & $\%$ & $\mathrm{~F}$ & $\%$ & $\mathrm{~F}$ & $\%$ & $F$ & $\%$ & $F$ & $\%$ \\
\hline 1 Baik & 1 & 4,5 & 8 & 36,4 & 11 & 50 & 2 & 9,1 & 22 & 16 \\
\hline 2 Cukup & 2 & 2,7 & 27 & 37 & 38 & 52 & 6 & 8,2 & 73 & 53 \\
\hline 3 Kurang & 0 & 0 & 16 & 37,2 & 23 & 53,4 & 4 & 9,3 & 43 & 31 \\
\hline Total & 3 & 2,2 & 51 & 37 & 72 & 52,1 & 12 & 8,6 & 138 & 100 \\
\hline
\end{tabular}

Berdasarkan tabel 7 diatas diketahui bahwa mayoritas responden yang mengetahui keputihan yang pengetahuannya cukup dan pekerjaan orang tuanya wiraswasta sebanyak 38 orang (52\%).

\section{PEMBAHASAN}

Pengetahuan adalah merupakan hasil "tahu” dan terjadi setelah orang melakukan penginderaan terhadap objek tertentu.Penginderaan terjadi melalui panca indera manusia, yakni : indera penglihataan, pendengaran, penciuman, rasa dan raba. Sebagian besar pengetahuan manusia diperoleh melalui mata dan telinga (Notoadmodjo, 2010).Pengetahuan mengenai keputihan adalah segala sesuatu yang diketahui remaja putri dan berkenaan dengan hal-hal mengenai keputihan.

Berdasarkan hasil penelitian dapat dilihat bahwaresponden yang mengetahui mengenai keputihan yang pengetahuannya baik berjumlah 22 orang (15,9\%), pengetahuan cukup 73 orang (52,9\%) dan pengetahuan kurang 43 orang (31,2\%). Hal ini menunjukkan meski sebagian besar pengetahuan pada remaja putri di SMA Negri 4 Medan sudah dalam kategori cukup tetapi masih ditemukan adanya pengetahuan yang kurang yaitu 
berjumlah 43 orang (31,2\%). Keadaan ini menjelaskan bahwa masih ada remaja putri yang tidak mengetahui keputihan.

Pengetahuan yang kurang ini dapat dipengaruhi oleh beberapa faktor yang mana pada penelitian ini ditemukan faktor dari sumber informasi yang berasal dari media elektronik sebanyak 93 orang $(67,4 \%)$, media cetak sebanyak 18 orang (13\%), dan orang/person sebanyak 27 orang $(19,6)$ yang sangat memiliki peran besar dalam memengaruhi pengetahuan remaja putri di SMA Negeri 4 Medan.

Faktor pendukung lain pada penelitian ini adalah pendidikan orang tua dimana hasilnya dapat dilihat pada table 3 diketahui bahwa mayoritas responden yang orang tuanya berpendidikan SMA sebanyak 77 orang (55,8\%) dan minoritas responden yang oranng tuanya berpendidikan perguruan tinggi sebanyak 61 (44,2\%). Dan faktor pendukung terakhir pada penelitian ini adalah pekerjaan orang tua di mana hasilnyamayoritas responden yang orang tuanya memiliki pekerjaan sebagai wiraswasta sebanyak 71 orang (52,2\%) dan minoritas responden yang oranng tuanya memiliki pekerjaan sebagai petani sebanyak 3 orang (2,2\%).

Hal ini tidak sejalan dengan hasil penelitian Dinda dkk 2016, di mana dapat diketahui bahwa pengetahuan remaja putri dalam penanganan keputihan dalam kategori baik sebesar 61,7\%, cukup sebesar 27,2\%, dan kurang sebesar 11,1\%. Dan hasil penelitian Paryono dkk 2016 dapat diketahui bahwa sebagian besar remaja sudah mendapatkan informasi mengenai keputihan sebanyak 25 siswi (61\%), dan yang belum pernah mendapat informasi sebanyak 16 siswi (39\%).

Ternyata mayoritas responden yang memiliki pengetahuan cukup mendapatkan informasi dari media elektronik, yaitu sebanyak 49 orang $(67,1 \%)$ artinya dapat disimpulkan media elektronik seperti HP, TV, dan internet sangat berperan dalam menambah wawasan responden pada zaman sekarng ini hal ini dikarenakan para remaja lebih senang mencari informasi dengan cara visual seperti melalui HP dibandingkan membaca buku.

Dari hasil penelitian pada tabel 6 di atas dapat dilihat bahwa responden yang berpengetahuan cukup mayoritas memiliki orang tua yang berpendidikan SMA sebanyak 37 orang (50.6\%), sehingga dapat diketahui ternyata orang tua berpendidikan SMA lebih kaya pengetahuan dan lebih baik dalam menyampaikan informasi ke pada anaknya. Hal ini sejalan dengan pendapat Nursalam, 2003 pendidikan dapat mempengaruhi seseorang termasuk juga perilaku seseorang akan pola hidup terutama dalam memotivasi untuk sikap berperan serta dalam pembangunan pada umumnya makin tinggi pendidikan seseorang makin mudah menerima informasi.

Dan dari hasil penelitian pada table 7 di atas dapat dilihat bahwa mayoritas orang tua responen yang bekerja sebagai wiraswasta pengetahuannya lebih baik sebanyak 38 orang (52\%). Orang tua/keluarga merupakan lingkungan pertama untuk mendapatkan pengetahuan/pendidikan.

Hal ini sesuai dengan pendapat Riamin (2016) yang menyatakan keterlibatan orang tua pada pendidikan sangat penting terbukti dari banyaknya dampak positif bagi anak khususnya remaja putri.Dalam keluargalah remaja putri dipersiapkan untuk membangun pengetahuan tentang perkembangan termasuk perkembangan fisik agar remaja putri mampu memasuki fase perkembangannya dunia lainnya seperti dunia orang dewasa, bahasa, adat istiadat dan kebudayaan.

\section{KESIMPULAN}

1. Berdasarkan hasil penelitian dari 138 responden, diketahui bahwa mayoritas responden yang mengetahui keputihan yang pengetahuannya cukup berjumlah 73 orang (52,9\%).

2. Berdasarkan hasil penelitian dari 138 responden, diketahui bahwa mayoritas responden yang mendapatkan sumber informasi melalui media elektronik sebanyak 93 orang $(67,4 \%)$.

3. Berdasarkan hasil penelitian dari 138 responden, diketahui bahwa mayoritas responden yang orang tuanya berpendidikan SMA sebanyak 77 orang (55,8\%).

4. Berdasarkan hasil penelitian dari 138 responden, diketahui bahwa mayoritas responden yang orang tuanya memiliki pekerjaan sebagai wiraswasta sebanyak 71 orang $(52,2 \%)$.

\section{SARAN}

1. Bagi SMA Negri 4 Medan

Diharapkan pihak sekolah SMA Negri 4 Medan hendaknya meningkatkan pengetahuan siswa dengan memberikan informasi tentang keputihan misalnya melalui majalah dinding (Mading), bukubuku atau majalah kesehatan, dll. Dan diharapkan bagi UKS SMA Negri 4 Medan agar mengaktifkan program KRR agar menambah pengetahuan masalah kesehatan reproduksi bagi para siswi.

2. Bagi Siswi SMA Negri 4 yang mengalami keputihan

Diharapkan agar siswi dapat menambah wawasan mereka melalui media elektronik, cetak, ataupun orang disekitar mereka khususnya mengenai penyebab terjadinya keputihan, jamur penyebab keputihan, $\mathrm{pH}$ normal vagina, dan penyebab keputihan secara normal

3. Bagi Masyarakat

\begin{tabular}{lccr}
\multicolumn{2}{c}{ Agar } & \multicolumn{2}{c}{ Masyarakat meningkatan } \\
pengetahuan & mengenai & keputihan & dengan \\
mengadakan & penyuluhan & kesehatan & tentang
\end{tabular}
keputihan.

4. Bagi Pelayanan Kesehatan

$$
\text { Agar Pelayanan Kesehatan }
$$
meningkatkan penyuluhan dan memberikan informasi tentang keputihan kepada masyarakat baik di fasilitas kesehatan yang terjangkau seperti puskesmas, rumah sakit, klinik dan fasilitas kesehatan lainnya.

5. Bagi Peneliti

Hasil Penelitian ini dapat di jadikan sebagai bahan referensi untuk melanjutkan 
penelitian yang berhubungan dengan keputihan dalam mencegah penyakit reproduksi pada remaja sehingga dapat menambah wawasan bagi peneliti berikutnya.

6. Bagi Peneliti

Hasil Penelitian ini dapat di jadikan sebagai bahan referensi untuk melanjutkan penelitian yang berhubungan dengan pemeriksaan payudara sendiri (SADARI) dalam mencegah penyakit kanker payudara pada remaja sehingga dapat menambah wawasan bagi peneliti berikutnya.

\section{DAFTAR PUSTAKA}

Kementrian Kesehatan Indonesia.2013. Profil Kesehatan Indonesia Tahun 2012. Jakarta: Kementrian Kesehatan Indonesia.

Leli, Indida. 2012. Gambaran Pengetahuan Remaja Putri Tentang Perineal Hygiene Di SMPIT As Salam
Pasar Minggu. Skripsi. Tersedia di http : // www.FIK UI. Com [ Diunduh 5 Desember 2015 ]

Nisman, A. W. 2011. Lima Menit Kenali Payudara Anda.Jogjakarta: Andi.

Rasjidi, Imam. 2010. 100 Question \& Answer Kanker Payudara Pada Wanita. Jakarta: Gramedia

Sari, Dilla Febria.2015. Hubungan Pengetahuan, Sikap dengan Tindakan Sadari Sebagai Deteksi Dini Kanker Payudara Pada Mahasiswi di Fakultas Kesehatan Masyarakat USU.Skripsi.[Online]. Tersedia di http://repository.usu.ac.id/bitstream/123456789/521 37/7/babi.pdf. [Diunduh 3 Desember 2015]

World Health Organization. 2012. The World Health Organization's Fight Against Cancer: Strategies That Prevent, Cure and Care. Tersedia di: http://www.who.int/cancer/modules Diakses tanggal: 1 Maret 2016. 